\title{
Autonomic dysregulation in ob/ob mice is improved by inhibition of angiotensin converting enzyme
}

Short title: Autonomic regulation in ob/ob mice

Aline M. Hilzendeger ${ }^{1,2,4}$, Andrey C. da Costa Goncalves ${ }^{2,4}$, Ralph Plehm², André Diedrich ${ }^{3}$, Volkmar Gross ${ }^{2}$, Joao B. Pesquero ${ }^{1}$, Michael Bader ${ }^{2}$.

${ }^{1}$ Department of Biophysics, Escola Paulista de Medicina, Federal University of São Paulo,

\author{
SP, Brazil \\ ${ }^{2}$ Max Delbrück Center for Molecular Medicine, Berlin, Germany \\ ${ }^{3}$ Department of Medicine, Division of Clinical Pharmacology, Autonomic Dysfunction \\ Service, Vanderbilt University School of Medicine, Nashville, TN, USA \\ ${ }^{4}$ These authors contributed equally to this work.
}

(Word count: 4359, abstract: 210,figures: 5)

Correspondence to:

Michael Bader, PhD, Max Delbrück Center for Molecular Medicine,

Robert-Rössle-Strasse 10, 13125 Berlin, Germany

Tel: ++49 309406 2193; Fax: ++49 309406 2110; email: mbader@mdc-berlin.de 


\section{Abstract}

The leptin deficient ob/ob mice are insulin resistant and obese. However, the control of blood pressure in this model is not well defined. The goal of this study was to evaluate the role of leptin and of the renin-angiotensin system in the cardiovascular abnormalities observed in obesity using a model lacking leptin. To this purpose, we measured blood pressure in ob/ob and control animals by radiotelemetry combined with fast Fourier transformation before and after both leptin and enalapril treatment. Autonomic function was assessed pharmacologically. Blood pressure during daytime was slightly higher in the ob/ob compared to control mice while no difference in heart rate was observed. Blood pressure response to trimetaphane and heart rate response to metoprolol were greater in ob/ob mice than in control littermates indicating an activated sympathetic nervous system. Heart rate response to atropine was attenuated. Baroreflex sensitivity and heart rate variability were blunted in ob/ob mice, while low frequency of systolic blood pressure variability was found increased. Chronic leptin replacement reduced blood pressure and reversed the impaired autonomic function observed in ob/ob mice. Inhibition of angiotensin converting enzyme by enalapril treatment had similar effects, prior to the loss of weight. These findings suggest that the renin-angiotensin system is involved in the autonomic dysfunction caused by the lack of leptin in ob/ob mice and support a role of this interplay in the pathogenesis of obesity, hypertension, and metabolic syndrome.

Keywords: ob/ob mice, leptin, obesity, hypertension, ACE inhibition, angiotensin II, autonomic dysfunction. 


\section{Introduction}

Obesity, hypertension, dyslipidemia and diabetes type II are the main risk factors which characterize metabolic syndrome when present simultaneously [1]. In an attempt to correlate obesity, diabetes type II and hypertension, Landsberg postulated an interesting model in which blood pressure (BP) increase is thought to be an unfortunate result of mechanisms that establish energy balance and limit weight gain. Although compelling evidences tightly correlated these diseases, no adipose tissue derived molecule was taken into account [2]. In fact, obesity itself can activate the sympathetic and the renin-angiotensin system, resulting in BP increase [3]. It is well described that both rodents and humans with obesity have higher levels of leptin [4] an important hormone expressed and secreted by adipose tissue proportionally to its size [5]. Leptin acting centrally [6] decreases body weight and adipose tissue mass through inhibiting appetite and food intake [7]. Moreover, intracerebroventricular administration of leptin increases renal sympathetic nerve activation and arterial pressure [6]. However, we have recently shown that the leptin receptor deficient $\mathrm{db} / \mathrm{db}$ mice had higher BP compared to control littermates, which was unexpectedly associated with increased sympathetic and attenuated parasympathetic drive [8], characterizing a cardiovascular autonomic dysfunction observed in obesity. In addition, since enalapril normalized the autonomic dysfunction in $\mathrm{db} / \mathrm{db}$ mice, angiotensin II (AngII) may be involved. This peptide regulates BP through actions in peripheral tissues and in the brain by activating the sympathetic nervous system [9] and altering baroreflex heart rate (HR) regulation [10]. Db/db mice only lack one type of leptin receptor and may still be responsive to this hormone. Thus it could not be excluded that the high circulating leptin levels in $\mathrm{db} / \mathrm{db}$ mice could be involved in the sympathetic activation and increased blood pressure (BP) in this model. To finally clarify the role of leptin and its relation to Ang II, we studied a model lacking leptin. Measurement of BP was performed in the leptin deficient ob/ob mice and control animals by 
radiotelemetry combined with fast Fourier transformation before and after both leptin and enalapril treatment. Autonomic function was as well assessed pharmacologically.

\section{Methods}

\section{Animals}

We studied adult 16-week-old, male ob/ob (B6.V-Lepob/J) mice and male ob/+ (C57BL/6J) purchased from Jackson Laboratory (Bar Harbor, ME, USA). The animals were maintained on a $12 \mathrm{~h}$ light $/ 12 \mathrm{~h}$ dark cycle at $22^{\circ} \mathrm{C}$ and had free access to standard chow (0.25\% sodium, SSNIFF Spezialitäten GmbH, Soest, Germany) and drinking water ad libitum. All experiments were conducted under these conditions. The local council on animal care approved the study according to requirements of the American Physiological Society. We measured body weights at weekly intervals. After recovery, telemetric baseline values were recorded for three days followed by enalapril (Sigma; 30mg/Kg.day) and by leptin (R\&D; $6 \mu \mathrm{g} /$ day) treatment in Alzet osmotic minipumps for 28 days. Enalapril was given to every mouse in the drinking water for seven days. A wash out period of seven days was allowed before osmotic minipumps containing leptin were implanted. After one week of leptin infusion, data were collected again.

\section{Pharmacological testing of autonomic function}

To evaluate autonomic control of BP, the following drugs were applied: muscarinic blockade was obtained with atropine $(2 \mathrm{mg} / \mathrm{kg}$; ob/+: $\mathrm{n}=8$; ob/ob: $\mathrm{n}=6), \beta_{1}$-adrenergic receptor blockade with metoprolol (4 mg/kg; ob/+: $\mathrm{n}=6$; ob/ob: $\mathrm{n}=5$ ), and ganglionic blockade with trimetaphane $(30 \mathrm{mg} / \mathrm{kg} ; \mathrm{ob} / \mathrm{+}: \mathrm{n}=5 ; \mathrm{ob} / \mathrm{ob}: \mathrm{n}=5)$. All of the substances were given intraperitoneally in the morning hours between 9 am and 12 am. Continuous beat-by-beat values of BP were recorded for 1 hour, after which the drugs were applied. Thereafter, beat- 
by-beat values were recorded for 1 additional hour. As in a former study [11], the values from the 45 th to the 60 th minute after drug injection were used to characterize the respective responses to avoid the measurement of stress-induced BP and HR changes. The protocols for the single injections were separated by $\geq 24$ hours. Drug administrations were not randomized. $\mathrm{BP}$ values in this study represent means of 3 days.

\section{Spectral Analysis}

Our approaches to radiotelemetry, spectral analysis, and calculations of baroreflex sensitivity (BRS) have been described elsewhere [11, 12]. For evaluation of cardiovascular function, the baroreceptor heart rate reflex and heart rate variability in the low frequency range (HRV-LF) were investigated using spontaneous changes in BP and HR. The power spectra of systolic blood pressure (SBP), pulse interval time series, and the cross spectra were calculated using fast Fourier transformation (FFT). Beat-to-beat values of detected R-R intervals and BP values were interpolated, low-pass filtered (cutoff $6 \mathrm{~Hz}$ ) and re-sampled at 12 Hz. Data segments of 43 seconds were used for spectral analysis. Linear trends were removed and power spectral density was estimated with the FFT-based Welch algorithm using segments of 512 data points with $50 \%$ overlapping and Hanning window. The power in the frequency range of low frequencies (LF: 0.25 to $0.6 \mathrm{~Hz}$ ) was calculated. Five representative intervals were chosen for spectral analysis and averaged according to the following criteria 1) steady state conditions, 2) no large sudden BP changes, 3) no artifacts. The frequency bands were adapted for analysis in mice considering the ranges of HR rate and breathing frequencies [13].

\section{Baroreflex sensitivity (BRS)}

Spontaneous baroreflex slope was calculated as the slope of the linear regression line between SBP and the subsequent R-R intervals using sequences defined as an episode of at 
least three heart beats with more than $0.01 \mathrm{mmHg}$ SBP per beat. The average values of all slopes with a correlation coefficient greater than 0.85 were calculated for sequences with rising BP (BRS- up). The BRS-LF was defined as the mean magnitude value of transfer function between SBP and R-R interval in the low-frequency band with negative phase and squared coherence value greater than 0.5. A negative phase indicates that BP leads R-Rinterval and a coherence value greater than 0.5 indicates a dominating linear relationship. The data analysis was performed with the PV-wave software (Visual Numerics, Houston, TX, U.S.A.).

\section{Statistics}

Data are presented as means \pm SEMs. Statistically significant differences in mean values were evaluated by ANOVA followed by Bonferroni posthoc test. Unpaired Student ttest was used independent samples. The value of $P \leq 0.05$ was considered significant.

\section{Results}

\section{Non-dipping arterial hypertension in ob/ob mice}

In the beginning of the telemetry measurements, following adaptation and recovery periods after probe implantations, body weight values were higher in ob/ob $(58.2 \pm 0.7 \mathrm{~g})$ when compared to ob/+ mice $(29.4 \pm 0.9 \mathrm{~g})$. As previously described $[14,15]$, blood glucose levels were increased in ob/ob compared to ob/+ mice at 16 weeks of age. Day and night mean arterial pressure (MAP) and heart rate (HR) are shown in Figure 1. Daytime MAP was higher in ob/ob $(112.5 \pm 1.2 \mathrm{mmHg})$ when compared to the controls $(104.2 \pm 2.6 \mathrm{mmHg}$; $\mathrm{P}<0.05$ : Figure 1A). No difference in BP between the groups was observed during the active night period. Thus, ob/ob mice showed an abnormal diurnal BP dipping status as can be seen 
by the reduction of the BP amplitude $(6.9 \pm 0.6$ vs. $2.0 \pm 0.2 \mathrm{mmHg})$. On the other hand, HR was not different between the groups at both day and night time, and showed a normal diurnal pattern (day: ob/ $+=484.7 \pm 6.8$ and ob/ob=511.1 \pm 10.2 bpm; night: $\mathrm{ob} /+=527.6 \pm 6.7$ and $\mathrm{ob} / \mathrm{ob}=551.6 \pm 10.1 \mathrm{bpm}$ : Figure 1B).

\section{Autonomic imbalance in ob/ob mice}

The activity of the autonomic nervous system was tested pharmacologically. BP response to trimetaphane and HR response to both atropine and metoprolol were measured. The ganglionic blockade with trimetaphane reduced blood pressure in both strains $(-28.9 \pm 0.9$ vs. $-43.3 \pm 2.5 \mathrm{mmHg}$; Figure $2 \mathrm{~A}$ ). However, the effect in obese mice was more pronounced than in controls $(\mathrm{P}<0.001)$. A lower HR response to atropine was observed in ob/ob mice compared to $\mathrm{ob} /+(102.2 \pm 3.6$ vs. $64.8 \pm 3.6 \mathrm{bpm} ; \mathrm{P}<0.001$; Figure $2 \mathrm{~B}) . \beta_{1}$-adrenergic receptor blockade with metoprolol provoked a higher decrease in HR in ob/ob than in ob/+ mice $(-37.8 \pm 3.0$ vs. $-97.2 \pm 6.0$ bpm; $\mathrm{P}<0.001$; Figure $2 \mathrm{C})$. These results suggest increased sympathetic and decreased parasympathetic tone in ob/ob mice. Sympathetic modulation of vascular tone was also analysed by the low-frequency systolic BP (LF-SBP) oscillations, derived from the Fourier analyses of the telemetric BP data [16]. Along with the trimetaphane and metoprolol results, LF-SBP was found increased in ob/ob mice $(2.5 \pm 0.3$ vs. $5.4 \pm 1.1$ $\mathrm{mmHg}^{2} ; \mathrm{P}<0.05$; Figure 3A). In mice, low-frequency HR oscillations (LF-HRV) are mediated through parasympathetic mechanisms [17]. In obese mice, LF-HRV was attenuated which corresponds with the decreased response to atropine ( $4.8 \pm 0.9$ vs. $1.8 \pm 0.6 \mathrm{msec}^{2} ; \mathrm{P}<0.05$; Figure 3B).

\section{Reduced baroreflex in ob/ob mice}

The baroreflex HR regulation was assessed by the sequence method and cross-spectral analysis. We have previously proven the validity of spontaneous BP and HR changes to 
characterize baroreflex sensitivity (BRS) in conscious mice [12]. BRS-up and BRS-LF were significantly decreased in ob/ob mice. Values for baroreflex sensitivity were substantially lower in ob/ob mice $(B R S-u p=0.36 \pm 0.10 \mathrm{msec} / \mathrm{mmHg}$, Figure $3 \mathrm{C} ; \mathrm{BRS}-\mathrm{LF}=0.79 \pm 0.19$ $\mathrm{msec} / \mathrm{mmHg}$, Figure 3D) compared to ob/+ animals (BRS-up $=1.09 \pm 0.25 \mathrm{msec} / \mathrm{mmHg}$ and BRS-LF= $1.96 \pm 0.47 \mathrm{msec} / \mathrm{mmHg} ; \mathrm{P}<0.05)$.

\section{Autonomic imbalance is reversed by chronic leptin treatment}

The same parameters were measured after one week of leptin treatment with osmotic minipumps. Leptin was given in a concentration $(6 \mu \mathrm{g} / \mathrm{day})$ previously described to restore glucose levels [18]. Leptin levels increased in both groups after one week of infusion (normal levels: $\mathrm{ob} /+=2.2 \pm 0.7$ and $\mathrm{ob} / \mathrm{ob}=0$ vs. after leptin: $\mathrm{ob} /+=23.1 \pm 2.2$ and $\mathrm{ob} / \mathrm{ob}=12.8 \pm 3.6$ $\mathrm{ng} / \mathrm{mL}$ ). At this time point, body weight of ob/ob was $47.1 \pm 1.2 \mathrm{~g}$ and ob/+ $29.7 \pm 0.9 \mathrm{~g}$.

Figure 4 shows BP changes after leptin treatment in ob/ob and control animals. Infusion of leptin decreased BP in ob/ob but not significantly in control mice. After one week of leptin treatment, changes in MAP in ob/+ mice was $-4.1 \pm 1.6 \mathrm{mmHg}$ and $-10.5 \pm 2.3$ $\mathrm{mmHg}$ in ob/ob mice $(\mathrm{P}<0.05)$. Leptin also increased baroreflex in both strains. Moreover, in leptin treated ob/ob mice BRS was restored to the values of ob/+ (BRS-LF: ob/+ before leptin: $1.9 \pm 0.5$ vs. ob/ob after leptin $2.5 \pm 0.5$; Figure 3D). LF-SBP was not changed after leptin treatment in the control animals. However, the increased LF-SBP observed in ob/ob mice was normalized by leptin (ob/+ baseline vs. ob/ob + leptin: $2.5 \pm 0.3$ vs. $1.8 \pm 0.7$ $\mathrm{mmHg}^{2}$; Figure 3A). Complete interruption of efferent autonomic traffic with trimetaphane resulted in a more pronounced reduction of $\mathrm{BP}$ in ob/ob mice during baseline, as shown in Figure 2A. After leptin treatment, the effect of trimetaphane in obese animals was restored to the control baseline levels $(\Delta \mathrm{BP}$ ob/+ baseline vs. ob/ob + leptin: $-28.9 \pm 0.9$ vs. $-24.2 \pm 1.2$ $\mathrm{mmHg}$ ). 


\section{Autonomic imbalance is reversed by $A C E$ inhibition}

Figure 5A shows the MAP changes during treatment with the angiotensin converting enzyme inhibitor enalapril, which had no effect on body weight. Enalapril reduced MAP in all animals and normalized circadian rhythm of BP in ob/ob mice. Furthermore, it significantly increased BRS-LF and LF-HRV and decreased LF-SBP (Figure 5B-D). In contrast, these parameters did not change significantly in control animals after treatment with enalapril.

\section{Discussion}

The major phenotypes of leptin deficient ob/ob mice are insulin resistance and obesity [19]. Often obesity is accompanied by a greater blood volume and increased cardiac output, which may lead to the development of hypertension [20]. This sequence of events may be the cause for the observed tight association between obesity and hypertension in most populations and suggests involvement of an adipose tissue-derived signal [21-23]. Leptin is the prime suspect because it was shown to elicit sympathetic activation when injected at high doses directly into the brain [24-26]. Indeed, circulating leptin concentrations are increased in patients with obesity and type 2 diabetes $[27,28]$. Leptin levels are also augmented in nondiabetic patients with hypertension [29, 30]. Furthermore, mice that overexpress leptin have elevated tail-cuff systolic BP [31].

However, we have recently shown that the $\mathrm{db} / \mathrm{db}$ mice, a model deficient in the major leptin receptor, exhibit elevated blood pressure (BP) associated with increased sympathetic and attenuated parasympathetic drive compared to the control littermates [8]. Nevertheless, the $\mathrm{db} / \mathrm{db}$ mice express other isoforms of leptin receptors and exhibit high circulating leptin levels. Thus, the well-described leptin-induced sympathoactivation may be involved in the cardiovascular autonomic dysfunction observed in the $\mathrm{db} / \mathrm{db}$ mice employing other receptors.

To clarify this issue, we analyzed the cardiovascular regulation in ob/ob mice completely lacking leptin. In our hands, ob/ob mice had slightly but significantly higher BP 
compared to the control littermates during the day. The published results about both acute and chronic BP measurements in ob/ob mice appear to be controversial. In several studies BP was evaluated $48 \mathrm{~h}$ after surgery, a time-frame not sufficient for stabilizing BP and day/night circadian rhythm. In contrast to previous findings but more according to our data, Swoap reported slightly increased blood pressure in ob/ob mice with levels of $108 \pm 2 \mathrm{mmHg}$ compared to $100 \pm 2 \mathrm{mmHg}$ in controls [32]. In that study, BP was also measured by telemetry like in ours. However, the telemetric devices were implanted into the aorta through the carotid artery which may have impaired the function of the carotid baroreceptors. For that reason and because our study focused on the autonomic regulation of blood pressure in the ob/ob mice, we implanted the telemetric device through the femoral artery.

Similar to what we found in the leptin receptor deficient $\mathrm{db} / \mathrm{db}$ mice, BP failed to drop during the inactive period in the ob/ob mice, a pattern that resembles non-dipping of BP often seen in hypertensive humans [33]. A disturbed circadian rhythm is often associated with metabolic disorders [34]. The Clock mutant mice, which lack a transcription factor involved in the generation of circadian rhythms, are hyperphagic and develop obesity. The resultant obesity is associated with increased blood glucose, cholesterol, and triglyceride levels, as observed in obese humans with metabolic syndrome [35]. Additionally, reduced circadian BP variation is associated with increased mortality [36].

More importantly, we observed an imbalance of the autonomic nervous system in the ob/ob mice. Regardless of the total absence of leptin, a higher sympathetic tone was unexpectedly found in these animals. Although no direct measurements of sympathetic activity was performed, the stronger effect of metoprolol and trimetaphane in the ob/ob mice support that notion. Along with these findings, the parameter LF-SBP, which is believed to represent the sympathetic tone to the periphery, was found increased in the ob/ob animals.

In a previous work, we underscored the validity of spontaneous BP and HR changes to characterize baroreflex sensitivity (BRS) in conscious mice [12], as shown previously in 
humans [37]. Baroreflex is attenuated in the ob/ob mice as can be seen by a reduction of BRSup and BRS-LF. Vagal regulation is also reduced in the obese animals. HR increase in response to intraperitoneal injection of atropine was approximately $40 \%$ reduced in the ob/ob compared to the control mice. In keeping with that finding, LF-HRV was found attenuated in the obese mice. Altogether, our data shows that ob/ob mice at 16 weeks of age present alterations of the autonomic homeostatic mechanisms that regulate BP and HR.

Chronic infusion of leptin reduced $\mathrm{BP}$ in our ob/ob mice probably by reducing sympathetic activity to the periphery. Accordingly, leptin infusion reduced the trimetaphane effect on BP and LF-SBP in ob/ob mice to the baseline level of control animals and normalized the altered baroreflex in these animals. Such reduction in BP by leptin has already been described in rats after intracerebroventricular infusion of the protein at low doses [38]. Taken together, our results suggest that leptin is not involved in the onset and maintenance of neither the obesity related hypertension nor the autonomic dysfunction related to type 2 diabetes. In the opposite, the resistance to leptin often observed in obese and diabetic patients [39] may even be causal for the increased BP in analogy to the ob/ob and $\mathrm{db} / \mathrm{db}$ mice.

In contrast, the renin-angiotensin system seems to be involved in this phenotype. Angiotensin II regulates BP via peripheral and central mechanisms. Centrally, angiotensin II activates the sympathetic nervous system. Furthermore, angiotensin II alters baroreflex heart rate regulation. We analyzed the inhibition of ACE by enalapril in the ob/ob mouse model, since we had found increased ACE activity in $\mathrm{db} / \mathrm{db}$ mice, which was later confirmed in another study [40]. ACE inhibition decreased BP in both groups and normalized the circadian rhythm in ob/ob mice suggesting that the increase in BP was at least in part due to the reninangiotensin system in this model. The associated improvement of baroreflex sensitivity and reducing sympathetic drive to the periphery by enalapril is consistent with a central mechanism. Markedly, inhibition of ACE had similar effects as leptin treatment in obese 
mice. Nevertheless, enalapril treatment did not change body weight in both groups excluding the possibility that weight loss could influence and restore autonomic dysfunction.

Our results show that blood pressure in the leptin deficient ob/ob mice is associated to an imbalance of the autonomic nervous system featured by sympathetic activation and reduction of the parasympathetic tone in association with diminished baroreflex sensitivity. Therefore, we conclude that ob/ob mice, like $\mathrm{db} / \mathrm{db}$ mice [8], are a model for the cardiovascular autonomic neuropathy seen in diabetic and obese patients [24, 25, 41] predisposing them to target organ damage and cardiac arrhythmias and ultimately increasing morbidity and mortality.

In conclusion, our data suggest that angiotensin II is involved in the autonomic imbalance associated with obesity and hypertension caused by leptin deficiency.

\section{Perspectives}

Our data suggesting that the renin-angiotensin system, but not leptin, is involved in non-dipping hypertension and autonomic imbalance related to obesity and type 2 diabetes may have experimental and clinical implications. Possibly the leptin resistance observed in patients is involved in the BP increase accompanying metabolic syndrome and obesity since we have unexpectedly shown that leptin reduces sympathetic activity and BP at least in ob/ob mice. Pharmacological activation of the leptin system or breaching of leptin resistance could, therefore, not only ameliorate obesity but also improve cardiovascular parameters. In addition, our data underscore the suitability of the RAS as drug target in the human metabolic syndrome.

\section{Acknowledgment}

We thank Ilona Kamer (Max Delbrück Center for Molecular Medicine, Berlin, Germany) for excellent technical assistance. 


\section{Sources of Funding}

This work was supported by grants from the Brazilian National Research Council (CNPq/CAPES), the Deutsche Forschungsgemeinschaft (GR1112/12-1, BA1374/16-1) and the Deutsche Akademische Austauschdienst (PROBRAL).

\section{Disclosures}

None.

\section{References}

1. Despres JP, Lemieux I (2006) Abdominal obesity and metabolic syndrome. Nature 444: $881-887$

2. Landsberg L (1986) Diet, obesity and hypertension: an hypothesis involving insulin, the sympathetic nervous system, and adaptive thermogenesis. Q J Med 61: 1081-1090

3. Stenvinkel P (2000) Leptin and blood pressure--is there a link? Nephrol Dial Transplant 15: 1115-1117

4. Maffei M, Halaas J, Ravussin E, Pratley RE, Lee GH, Zhang Y, Fei H, Kim S, Lallone R, Ranganathan S, et al. (1995) Leptin levels in human and rodent: measurement of plasma leptin and ob RNA in obese and weight-reduced subjects. Nat Med 1: 1155-1161

5. Friedman JM, Halaas JL (1998) Leptin and the regulation of body weight in mammals. Nature 395: 763-770

6. Rahmouni K, Morgan DA (2007) Hypothalamic arcuate nucleus mediates the sympathetic and arterial pressure responses to leptin. Hypertension 49: 647-652

7. Haynes WG (2000) Interaction between leptin and sympathetic nervous system in hypertension. Curr Hypertens Rep 2: 311-318 
8. Goncalves AC, Tank J, Diedrich A, Hilzendeger A, Plehm R, Bader M, Luft FC, Jordan J, Gross V (2009) Diabetic hypertensive leptin receptor-deficient db/db mice develop cardioregulatory autonomic dysfunction. Hypertension 53: 387-392

9. Carlson SH, Wyss JM (2008) Neurohormonal regulation of the sympathetic nervous system: new insights into central mechanisms of action. Curr Hypertens Rep 10: 233-240

10. Xue B, Gole H, Pamidimukkala J, Hay M (2003) Role of the area postrema in angiotensin II modulation of baroreflex control of heart rate in conscious mice. Am J Physiol Heart Circ Physiol 284: H1003-1007

11. Gross V, Tank J, Obst M, Plehm R, Blumer KJ, Diedrich A, Jordan J, Luft FC (2005) Autonomic nervous system and blood pressure regulation in RGS2-deficient mice. Am J Physiol Regul Integr Comp Physiol 288: R1134-1142

12. da Costa-Goncalves AC, Tank J, Plehm R, Diedrich A, Todiras M, Gollasch M, Heuser A, Wellner M, Bader M, Jordan J, Luft FC, Gross V (2008) Role of the multidomain protein spinophilin in blood pressure and cardiac function regulation. Hypertension 52: 702707

13. Gross V, Tank J, Partke HJ, Plehm R, Diedrich A, da Costa Goncalves AC, Luft FC, Jordan J (2008) Cardiovascular autonomic regulation in Non-Obese Diabetic (NOD) mice. Auton Neurosci 138: 108-113

14. Drel VR, Mashtalir N, Inytska O, Shin J, Li F, Lyzogubov VV, Obrosova IG (2006) The leptin-deficient (ob/ob) mouse: a new animal model of peripheral neuropathy of type 2 diabetes and obesity. Diabetes 55: 3335-3343

15. Vareniuk I, Pavlov IA, Drel VR, Lyzogubov VV, Ilnytska O, Bell SR, Tibrewala J, Groves JT, Obrosova IG (2007) Nitrosative stress and peripheral diabetic neuropathy in leptin-deficient (ob/ob) mice. Exp Neurol 205: 425-436 
16. Japundzic N, Grichois ML, Zitoun P, Laude D, Elghozi JL (1990) Spectral analysis of blood pressure and heart rate in conscious rats: effects of autonomic blockers. J Auton Nerv Syst 30: 91-100

17. Tank J, Jordan J, Diedrich A, Obst M, Plehm R, Luft FC, Gross V (2004) Clonidine improves spontaneous baroreflex sensitivity in conscious mice through parasympathetic activation. Hypertension 43: 1042-1047

18. Harris RB, Zhou J, Redmann SM, Jr., Smagin GN, Smith SR, Rodgers E, Zachwieja JJ (1998) A leptin dose-response study in obese (ob/ob) and lean (+/?) mice. Endocrinology 139: 8-19

19. Lindstrom P (2007) The physiology of obese-hyperglycemic mice [ob/ob mice]. ScientificWorldJournal 7: 666-685

20. Kopelman PG (2000) Obesity as a medical problem. Nature 404: 635-643

21. Weyer C, Pratley RE, Snitker S, Spraul M, Ravussin E, Tataranni PA (2000) Ethnic differences in insulinemia and sympathetic tone as links between obesity and blood pressure. Hypertension 36: 531-537

22. Rahmouni K, Correia ML, Haynes WG, Mark AL (2005) Obesity-associated hypertension: new insights into mechanisms. Hypertension 45: 9-14

23. Gentile CL, Orr JS, Davy BM, Davy KP (2007) Modest weight gain is associated with sympathetic neural activation in nonobese humans. Am J Physiol Regul Integr Comp Physiol 292: R1834-1838

24. Ewing DJ (1996) Diabetic autonomic neuropathy and the heart. Diabetes Res Clin Pract 30 Suppl: $31-36$

25. Dunbar JC, Hu Y, Lu H (1997) Intracerebroventricular leptin increases lumbar and renal sympathetic nerve activity and blood pressure in normal rats. Diabetes 46: 2040-2043 
26. Haynes WG, Morgan DA, Walsh SA, Mark AL, Sivitz WI (1997) Receptor-mediated regional sympathetic nerve activation by leptin. J Clin Invest 100: 270-278

27. Nyholm B, Fisker S, Lund S, Moller N, Schmitz O (1997) Increased circulating leptin concentrations in insulin-resistant first-degree relatives of patients with non-insulin-dependent diabetes mellitus: relationship to body composition and insulin sensitivity but not to family history of non-insulin-dependent diabetes mellitus. Eur J Endocrinol 136: 173-179

28. Considine RV, Sinha MK, Heiman ML, Kriauciunas A, Stephens TW, Nyce MR, Ohannesian JP, Marco CC, McKee LJ, Bauer TL, et al. (1996) Serum immunoreactive-leptin concentrations in normal-weight and obese humans. N Engl J Med 334: 292-295

29. Asakawa H, Tokunaga K, Kawakami F (2001) Relationship of leptin level with metabolic disorders and hypertension in Japanese type 2 diabetes mellitus patients. J Diabetes Complications 15: 57-62

30. Adamczak M, Kokot F, Wiecek AW (2000) Relationship between plasma renin profile and leptinaemia in patients with essential hypertension. J Hum Hypertens 14: 503-509

31. Aizawa-Abe M, Ogawa Y, Masuzaki H, Ebihara K, Satoh N, Iwai H, Matsuoka N, Hayashi T, Hosoda K, Inoue G, Yoshimasa Y, Nakao K (2000) Pathophysiological role of leptin in obesity-related hypertension. J Clin Invest 105: 1243-1252

32. Swoap SJ (2001) Altered leptin signaling is sufficient, but not required, for hypotension associated with caloric restriction. Am J Physiol Heart Circ Physiol 281: H24732479

33. O'Brien E, Sheridan J, O'Malley K (1988) Dippers and non-dippers. Lancet 2: 397

34. Loboda A, Kraft WK, Fine B, Joseph J, Nebozhyn M, Zhang C, He Y, Yang X, Wright C, Morris M, Chalikonda I, Ferguson M, Emilsson V, Leonardson A, Lamb J, Dai H, Schadt E, Greenberg HE, Lum PY (2009) Diurnal variation of the human adipose transcriptome and the link to metabolic disease. BMC Med Genomics 2: 7 
35. Williams DL, Schwartz MW (2005) Out of synch: Clock mutation causes obesity in mice. Cell Metab 1: 355-356

36. Sturrock ND, George E, Pound N, Stevenson J, Peck GM, Sowter H (2000) Nondipping circadian blood pressure and renal impairment are associated with increased mortality in diabetes mellitus. Diabet Med 17: 360-364

37. Parlow J, Viale JP, Annat G, Hughson R, Quintin L (1995) Spontaneous cardiac baroreflex in humans. Comparison with drug-induced responses. Hypertension 25: 1058-1068

38. Correia ML, Morgan DA, Sivitz WI, Mark AL, Haynes WG (2001) Leptin acts in the central nervous system to produce dose-dependent changes in arterial pressure. Hypertension 37: 936-942

39. Mark AL, Correia ML, Rahmouni K, Haynes WG (2002) Selective leptin resistance: a new concept in leptin physiology with cardiovascular implications. J Hypertens 20: 12451250

40. Senador D, Kanakamedala K, Irigoyen MC, Morris M, Elased KM (2009) Cardiovascular and autonomic phenotype of db/db diabetic mice. Exp Physiol 94: 648-658

41. Esler M, Lambert G, Brunner-La Rocca HP, Vaddadi G, Kaye D (2003) Sympathetic nerve activity and neurotransmitter release in humans: translation from pathophysiology into clinical practice. Acta Physiol Scand 177: 275-284 


\section{Figure Legends}

Figure 1. Circadian variation of MAP (A) and HR (B) for ob/+ (n=6, white bars) and ob/ob ( $n=7$, black bars) mice. MAP was higher in ob/ob mice only during the day. HR was higher in both groups at night $(* \mathrm{P}<0.05, * * \mathrm{P}<0.01)$.

Figure 2. Effect of trimetaphane $(30 \mathrm{mg} / \mathrm{Kg})$ on blood pressure $(\triangle \mathrm{MAP} ; \mathrm{A})$ and of atropine $(2 \mathrm{mg} / \mathrm{Kg}$; B) and metoprolol $(4 \mathrm{mg} / \mathrm{Kg}$; $\mathrm{C})$ on HR in ob/+ (black bars) and ob/ob mice (white bars) $(* * * \mathrm{P}<0.001)$

Figure 3. Autonomic regulation in ob/ob mice (A) Low-frequency variability of systolic blood pressure (LF-SBP) indicating sympathetic outflow to the periphery. (B) Low-frequency heart rate variability (LF-HRV). (C) Spontaneous baroreflex sensitivity up-sequences (BRSup) calculated with the sequence method. (D) Spontaneous baroreflex sensitivity in the low frequency band (BRS-LF) calculated as the mean value of the transfer function between SBP and pulse intervals. All parameters were measured before and after leptin infusion in both groups $(* \mathrm{P}<0.05, * * \mathrm{P}<0.01, * * * \mathrm{P}<0.001)$.

Figure 4. Leptin treatment of ob/ob mice. Change of mean arterial pressure ( $\triangle \mathrm{MAP}$ ) by leptin treatment in $\mathrm{ob} /+$ and $\mathrm{ob} / \mathrm{ob}$ mice $(* \mathrm{P}<0.05)$.

Figure 5. Effect of ACE inhibition with enalapril on blood pressure and autonomic function in $\mathrm{ob} / \mathrm{ob}$ and $\mathrm{ob} /+$ mice. (A) Circadian variation of mean arterial pressure ( $\triangle \mathrm{MAP})$ in basal conditions and after enalapril treatment. (B) Low-frequency variability of spontaneous baroreflex sensitivity (BRS-LF). (C) Low-frequency systolic blood pressure variability (LFSBP). (D) Low-frequency heart rate variability (LF-HRV) $\left({ }^{*} \mathrm{P}<0.05\right)$. 
A

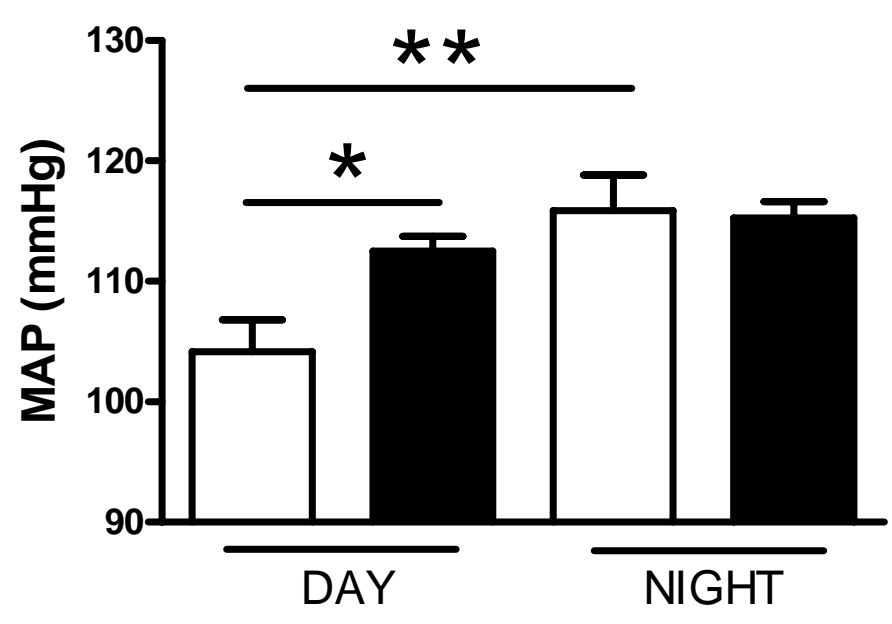

B

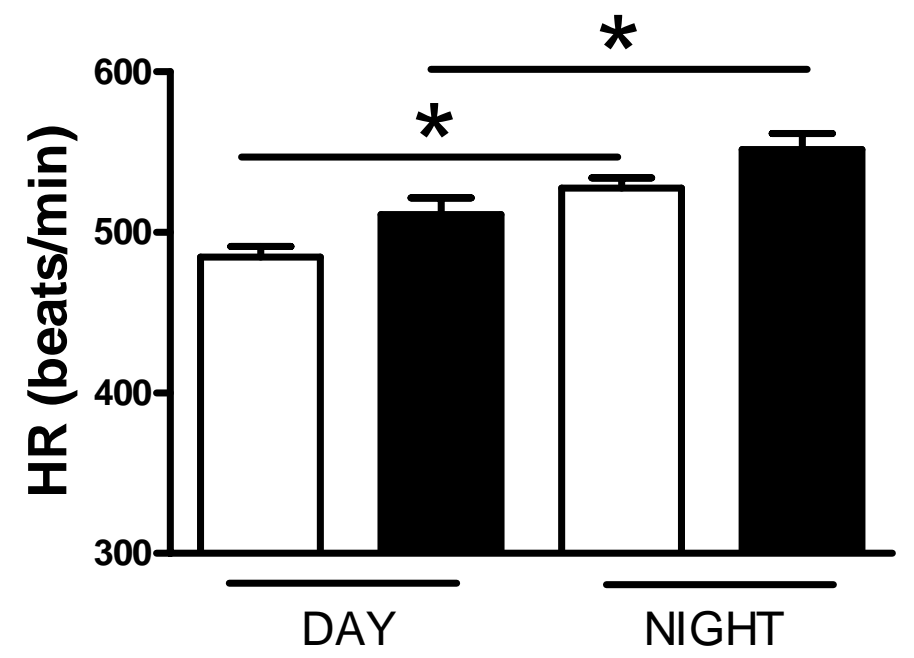

Figure 1 
Trimetaphane
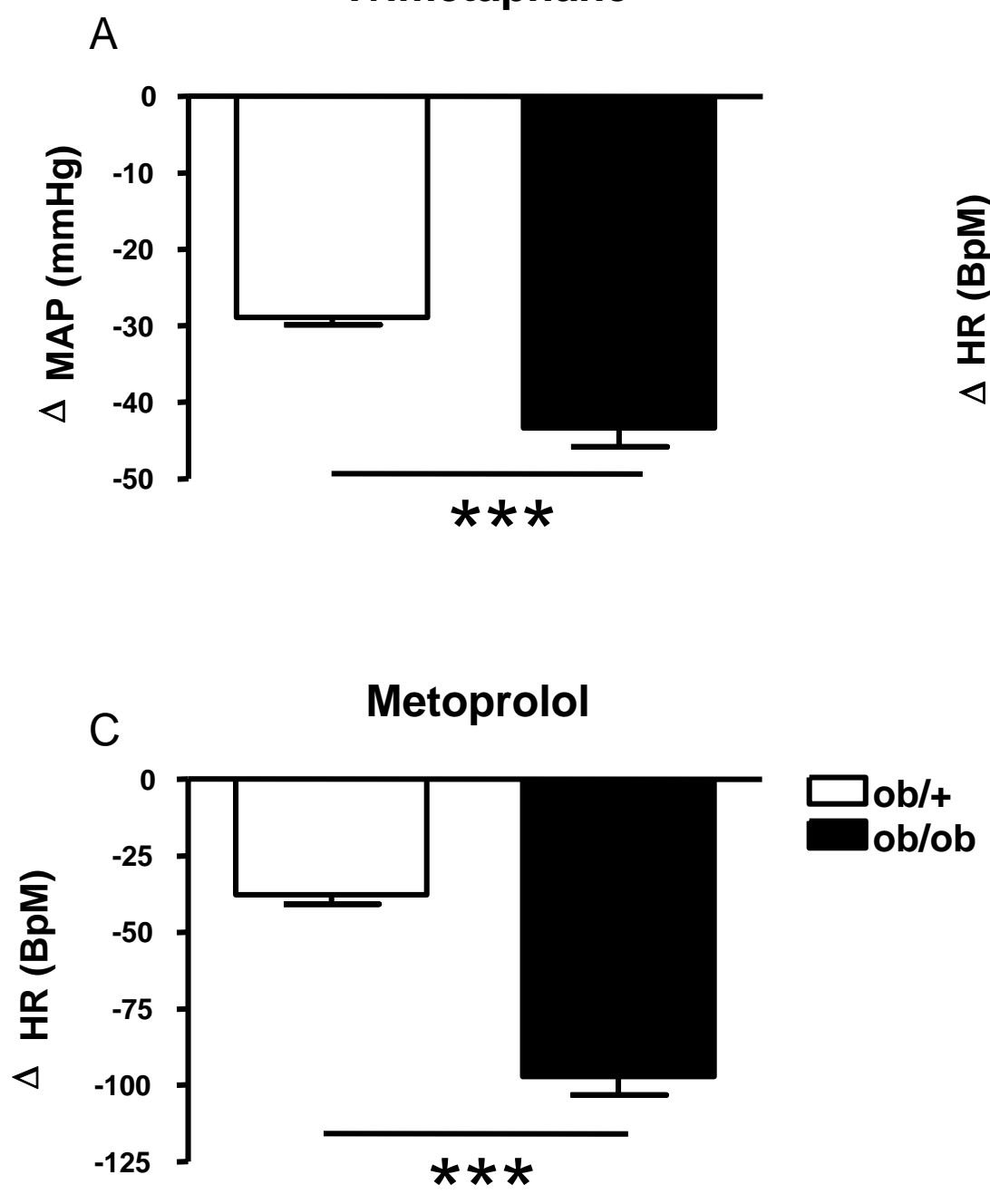

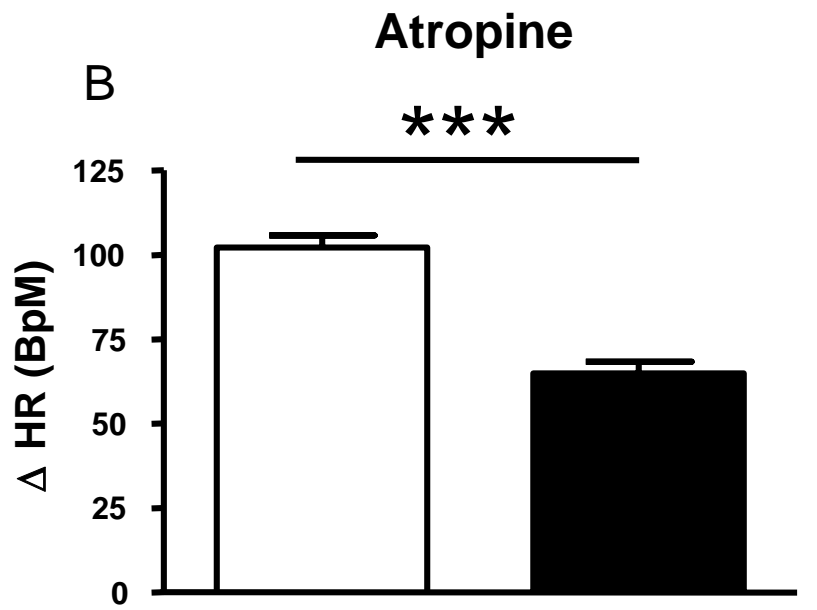



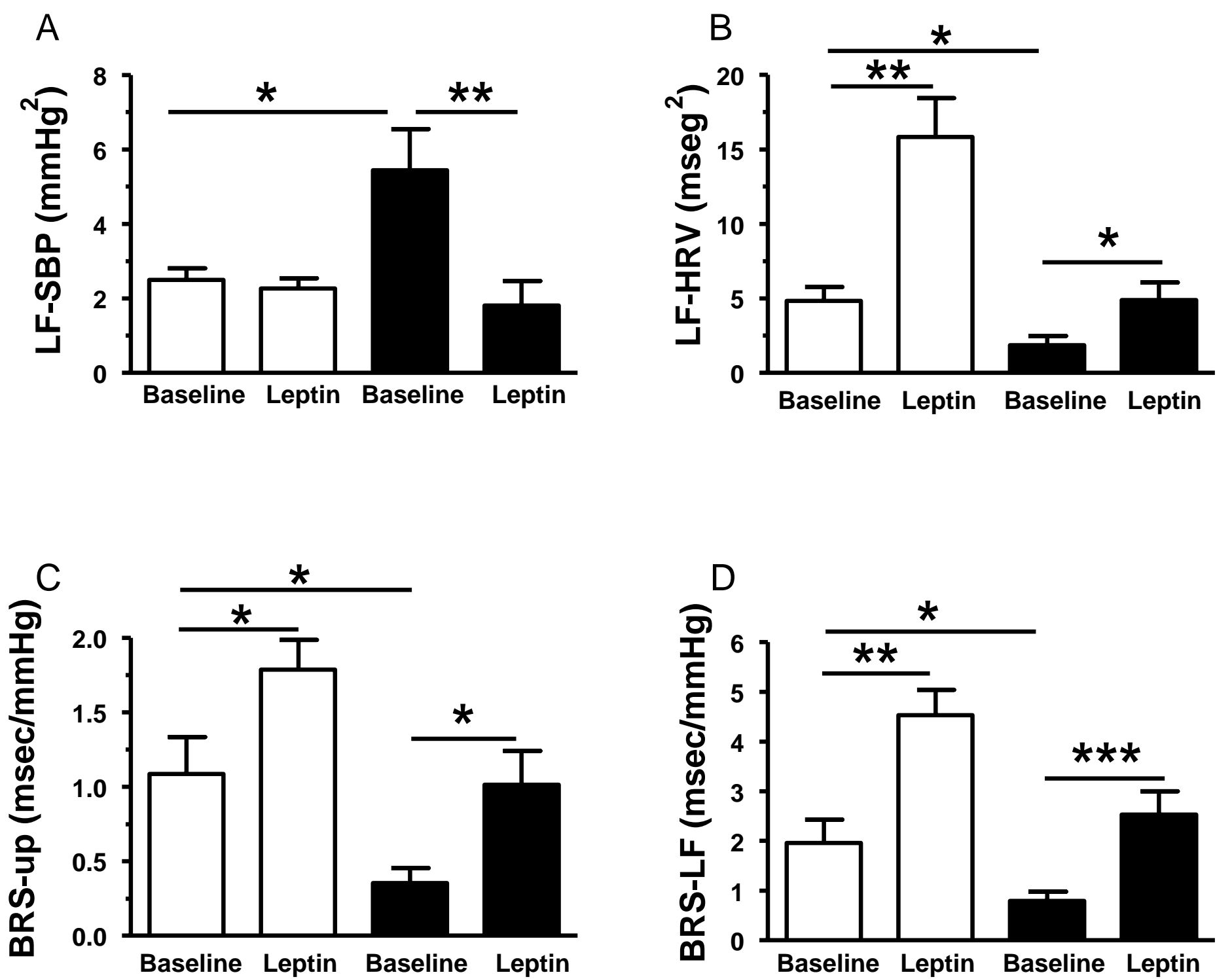

Figure 3 


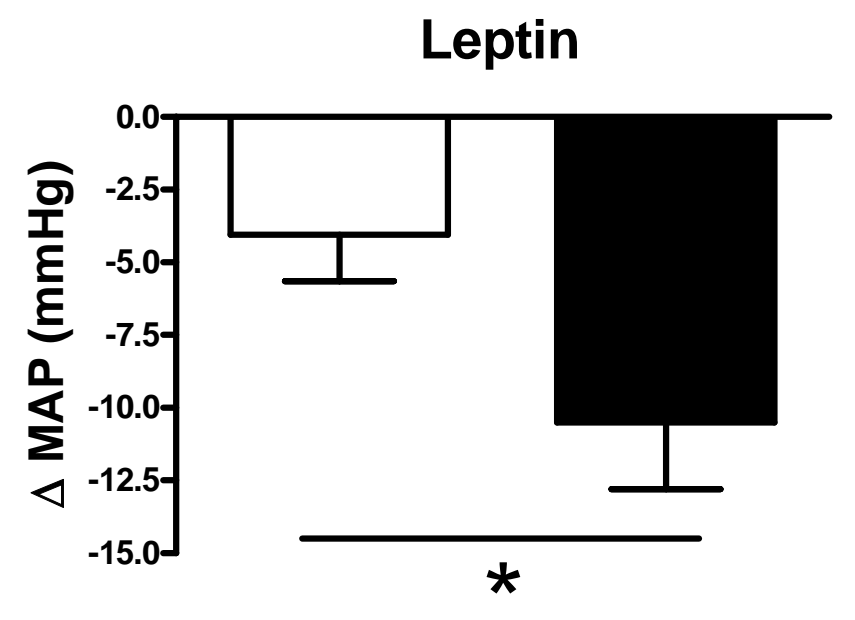

Figure 4 

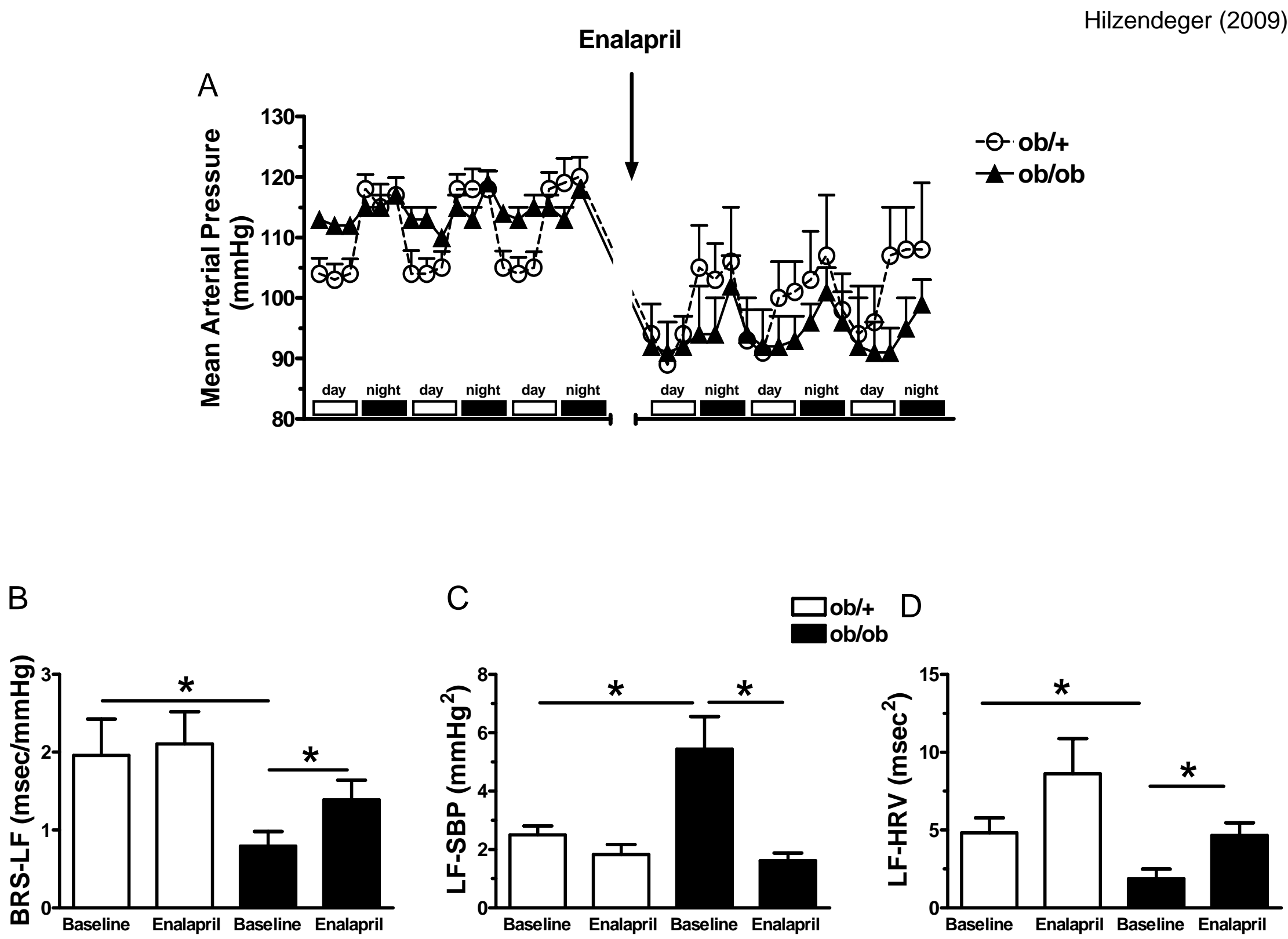

Figure 5 